

\title{
Luces y sombras en el Siglo de las luces español: apreciaciones sobre la influencia de las ideas venidas de Europa, reflejadas en la obra Noches Lúgubres de José Cadalso
}

\author{
Gracineia dos Santos Araújo ${ }^{1}$ \\ Universidad de Salamanca
}

\begin{abstract}
Resumen: El presente trabajo pretende hacer una breve reflexión sobre la influencia de las ideas venidas de Europa y todo lo que ello supone en la sociedad española dieciochesca, todavía rural y agraria, por medio de la óptica de José Cadalso y Vázquez, en la obra Noches Lúgubres (1789-1790). El autor, motivado por la llegada del pensamiento francés del Siècle des Lumières, se basa en la razón para encontrar una posible solución para los problemas que afligen a la sociedad, manifestándose contra lo tradicional y lo dogmático.
\end{abstract}

Palabras clave: José Cadalso. Siglo de las Luces. Noches lúgubres.

El Siglo XVIII, también llamado Siglo de las Luces, Ilustración o Iluminismo, es una de las épocas más relevantes para la historia de la cultura y literatura de España. En este período, el país enfrenta una serie de crisis ideológicas, lo que favorece un cambio sustancial en todos los ámbitos de la sociedad, especialmente en el terreno literario.

El Siglo de las Luces se inicia en el país con la llegada de ideas venidas de Europa, favoreciendo el movimiento político, filosófico y cultural. Los acontecimientos de más allá del Pirineo, como la Revolución Francesa de 1789, vienen acompañados de un gran progreso económico y desarrollo científico.

El pensamiento francés del Siècle des Lumières, sumado a la aportación del raciocinio de otros países, como pueden ser Italia, Inglaterra u Holanda, entre otros, pretende arrancar a España de la ruralidad y de la sombra eclesiástica, como factor indispensable para incorporarse a la modernidad. En este sentido, la llegada de nuevas ideas y costumbres dan nuevo matiz a la sociedad. No obstante, a esa España dieciochesca, todavía rural y arcaica, heredera de la debilidad política, militar y cultural de finales del siglo XVII, las novedades traídas por los nuevos aires que vienen de países con mayor libertad de pensamiento, "tardaron en llegar y no fueron bien recibidas ni asimiladas en su integridad", subraya Aguilar Piñal (1996, p.13).

\footnotetext{
${ }^{1}$ Investigadora postdoctoral - Universidad de Salamanca, USAL, (actual), España, Departamento de Literatura Española e Hispanoamericana; Doctora en Español: Lingüística, Literatura y Comunicación - Universidad de Valladolid, UVA, España (2015). E-mail: gracineia@ hotmail.com. 
R E V I S T A Estudos Literários - N. 30 - 2015.2-Gracineia dos Santos Araújo

La influencia francesa abarca principalmente la moda y las costumbres de la sociedad, pero también ejerce papel sumamente relevante en la formación del pensamiento español. Más que nunca, surge la necesidad de "estar al día" y superar el complejo de inferioridad al que estuvo sometido el país durante mucho tiempo. Sin embargo, las novedades venidas de Francia han sido algunas de carácter pasajero, como la moda introducida a los trajes y los afeites de damas y caballeros, entre otros factores, según subraya Martín Gaite (1998, p. 45) en el fragmento a continuación:

Los complicados peinados que la moda francesa había introducido hacían necesaria la ayuda cotidiana de un peluquero, que solía trabajar a domicilio y que constituía un indispensable símbolo de lujo. Todas las mujeres ansiaban tener peluquero particular, y si podía ser de nacionalidad francesa y no peinarlas más que a ellas, mejor.

La influencia francesa se impone rápidamente en las costumbres españolas, afectando a todas las capas de la población. Ante esta realidad, surge en la sociedad "una tendencia a glorificar la novedad, el instante presente, las apariencias, un deseo de exhibición, de 'aparentar', subraya Martín Gaite (1988. p 43). La moda y el cortejo son uno de los abundantes ejemplos de la presencia e influencia del ideario francés en la sociedad española. Todavía según destaca Martín Gaite (1988), la palabra moda se aplica para referirse a las novedades, normalmente de carácter poco duradero:

Modas las hubo en el vestir, en la afectación al hablar, en los hábitos familiares, como beber chocolate a todas horas o tomar rape francés, en los paseos públicos (...) en los bailes de máscaras en carnaval, y en los establecimientos conocidos como casas-café, competidores novísimos de las tradicionales tabernas o botillerías, pero donde no se servían bebidas alcohólicas (MARTÍN GAITE, 1988, p. 43).

En la literatura, algunos escritores satirizan ferozmente esta idea de moda por tratarse, en general, de una novedad extraña y vanidosa. Sin embargo, aunque hacen críticas contundentes a esta nueva ilustración de la sociedad española, bajo la influencia francesa, no se contienen y se adhieren al gusto adquirido a través de los vientos que soplaban desde más allá del Pirineo. José Cadalso y Vázquez es uno de los ejemplos más contundentes de la influencia europea.

Las "novedades" venidas de Europa tienen lugar en plena Guerra de Sucesión y coinciden con reformas sociales, como el aumento y reformulación del Ejército y, por consiguiente, el florecimiento de una España como nación supuestamente unitaria y centralizada. Sin embargo, según destaca Aguilar Piñal (1996, p.15), "la novedad más importante fue, sin duda, la pragmática real de 10 de mayo de 1715 que dio origen a la 


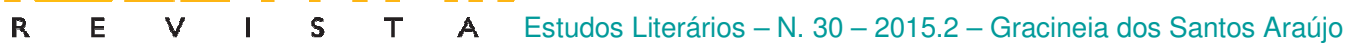

Corona de España, en la que se integraban los antiguos reinos y provincias, tanto peninsulares como insulares y coloniales".

Además del florecimiento de una España como nación unitaria y centralizada, son hechos importantes para el futuro del país el surgimiento de los colegios de abogados, 1732, y la creación de los ministerios y del Consejo de Ministros (1787). Por otro lado, fenómenos como el desarrollo de la industria son evidentes, lo que ocasiona la libertad del comercio decretada en 1778. Con todas esas aportaciones, el país se va modernizando y la referida modernización se refleja y se concretiza en la numeración de las casas por manzanas; en la construcción y restauración de paseos públicos; en la difusión de la prensa periódica; en el transporte de viajeros o el servicio de correos, entre otras creaciones del siglo XVIII.

Sin duda, es importante destacar que el Siglo de las Luces en España es heredero de un panorama desolador, que venía desde finales del siglo XVII, principalmente en lo que se refiere al ámbito de la cultura: "Para mí nunca sale el sol. Las horas todas se pasan en igual oscuridad para mí. Cuantos objetos veo en lo que llaman día, son a mí vista fantasmas, visiones y sombras" (CADALSO, 2006. p. 385). En estas circunstancias, las tres grandes universidades como la Universidad de Salamanca, la Universidad de Valladolid y la Universidad de Alcalá de Henares “agonizaban en manos de los catedráticos más tradicionales, empeñados en una repetición absurda de los tópicos escolásticos y en defensa intransigente del sistema galénico", subraya Aguilar Piñal (1996. p.17). Ante este panorama desolador de los últimos años del siglo XVII, un grupo de científicos y médicos deciden romper abiertamente con los principios tradicionales de la sociedad en que vivían, pasando a la historia como pioneros de la Ilustración en España, aunque en el principio se les atribuye el término despectivo de novatores.

En el ámbito literario, surge la literatura satírica a partir de la llegada de lo que podemos denominar nuevos aires, venidos de Europa. Las obras de autores como Ramón de la Cruz se convierten en novedad teatral y tienen una prolongada influencia en las clases sociales más populares. El repertorio de estas obras se compone de imitaciones, traducciones y reediciones de textos de diversos países, y que ya tienen éxito en toda Europa. La competencia de piezas extranjeras, sin embargo, favorece la disminución de la preferencia de los espectadores españoles por las obras de producción nacional.

En efecto, la Ilustración en España tiene un carácter colectivo y supone un relevante fenómeno motivador de la reforma del país contra la decadencia nacional y el aislamiento del resto de Europa. El deseo colectivo de construir una España nueva, a partir de la influencia europea, es una característica que marca el siglo XVIII. En este sentido, es importante 
R E V I S T A Estudos Literários - N. 30 - 2015.2-Gracineia dos Santos Araújo

recordar que muchos fermentos de carácter individual se sumaron a la colectividad de la sociedad con la avidez de cambios sociales radicales.

Las fundaciones de Colegios de Cirugía de Cádiz (1748) y Barcelona (1760); Colegios de Artillería de Barcelona (1750), entre otras, desde un punto de vista institucional, son bastante significativas para el cambio de la sociedad española en el siglo XVIII. En estas instituciones se pretende contar con personal científico y técnicamente cualificado, capaz de redimensionar y revolucionar las instituciones más tradicionales. A este movimiento de progreso científico no se suman, en general, las universidades, instituciones de larga tradición histórica, a las que habían acudido los mejores catedráticos españoles. La no adhesión de las universidades a lo nuevo no es solo un fenómeno español, sino también de algunas universidades europeas como Cambridge u Oxford, entre otras, que demuestran su carácter conservador, con respecto a otras universidades.

En el campo literario, la libertad de expresión en la España dieciochesca se introduce a la constitución de 1812, que promulga en su artículo 131 la libertad de imprenta.

Durante todo el siglo XVIII el pensamiento, lejos de ser libre, había de ser expresado con múltiples precauciones para no incidir en culpabilidad legal por insinuar la más leve crítica a los dos poderes establecidos, la Iglesia católica y la Monarquía, o en expresión más usual, el Altar y el Trono (AGUILAR PIÑAL, 1996. p. 20).

A causa de la censura ejercida por el Estado y la Iglesia, muchos escritores, entre ellos Cadalso, autocensuran sus obras como forma de librarse de la persecución de las jerarquías dominantes. Por un lado, la censura gubernamental; por otro, la inquisitorial, ya que no se puede oponerse a las buenas costumbres, a la fe católica y a la familia real.

En la muy católica España dieciochesca, todos los libros sospechosos tienen que pasar por la censura, sean nacionales o importados, para evitar atentar contra las regalías del Estado y de la Iglesia. Por ello, muchos escritores y personajes de la vida pública son castigados y condenados por el Santo Oficio de la Inquisición, con el visto bueno del poder político, a causa de su "sospechosa" trayectoria ideológica. En las reprobaciones inquisitoriales se incluyen a todos los que se atrevieran a pisar el umbral de la ortodoxia vaticana. La vigilancia y condena de la censura no se destina solamente a los escritores y filósofos españoles, sino que se amplia, además, a las empresas periodísticas, con embargos y prohibiciones de sus textos, tanto en el ámbito nacional como internacional.

En medio de este panorama de conflictos internos, siempre bajo la influencia de ideas venidas de varios países de Europa, surge una nueva cultura nacida a raíz del pensamiento ilustrado. La nueva cultura, el nuevo pensamiento, lentamente se arraigan y se extienden con 
R E V I S T A Estudos Literários - N. 30 - 2015.2-Gracineia dos Santos Araújo

firmeza en el territorio nacional. Los pensadores ilustrados en España no optan por alcanzar la libertad y los cambios sociales a cualquier precio, tampoco pretenden la desaparición del Antiguo Régimen, sino que intentan trazar un nuevo rumbo de la historia; abrir el país a nuevas ideas, con un intento de europeización del país por medio de ideas sólidas, en búsqueda de una sociedad más libre e igualitaria.

El hombre ilustrado no hace uso exclusivo de la razón, sino también de la emoción, la sensibilidad, la cual se refleja no solo en las letras, sino en los más variados ámbitos de la ciencia: las matemáticas, la química, entre otras. Se trata de una sensibilidad que permite entender la sociedad española como un conjunto de intereses comunes, diferentemente de los siglos pasados, con repercusiones novedosas en las costumbres y en el comportamiento social, reflejadas en las instituciones y en la consciencia histórica. El hombre ilustrado no sale de las capas menos favorecidas, analfabetas y rurales o periféricas de la sociedad, sino de una elite social; aspira a erradicar la pobreza y estimular el trabajo; es reformista y no concibe el origen divino de los reyes.

\section{José Cadalso y las Noches Lúgubres}

Noches Lúgubres (1789-1790) es una de las obras más relevantes del romanticismo español. Bastante antes de su publicación, el texto provoca interés y despierta la crítica e inquietudes en muchos escritores. Se trata de una obra que se destaca por su radical novedad literaria y por ser, según Azorín (1926), la primera obra romántica española, cuyo protagonista padece del más profundo dolor humano y no encuentra remedio para sus penas más que en la naturaleza. Es una obra lírica y, como la gran producción romántica, manifiesta una tendencia agenérica. Tiene rasgos teatrales, pero no llega a formar parte de este género. Su forma dialogada remite al Renacimiento y a la antigüedad clásica, cuya trascendentalidad se da a causa de las cuestiones que trae a la luz el yo lírico.

La obra de Cadalso tiene un carácter sumamente innovador, ampliamente diferente de la literatura de la época, y forma parte de un conjunto de obras que procura delinear un retrato de una sociedad impregnada de modelos tradicionales, tanto en el ámbito civil como eclesiástico. La historia de amor de Tediato es precursora del romanticismo español, cuyas adversidades llevan al protagonista a exteriorizar su desacuerdo con las jerarquías civiles y eclesiásticas; no entiende cómo el ser humano, siendo tan frágil, puede vivir tanto tiempo bajo el control de la Iglesia y del Estado: 
Un cuerpo tan frágil como el nuestro; agitado por tantos humores; compuesto de tantas partes invisibles; sujeto a tan frecuentes movimientos; lleno de tantas inmundicias; dañado por nuestros desórdenes y, lo que es más, movido por una alma ambiciosa, envidiosa, vengativa, iracunda, cobarde y esclava de tantos tiranos (CADALSO, 2006. p. 375).

Cadalso utiliza en Noches Lúgubres el escenario de la España del siglo XVIII para denunciar la división de clase y la inmovilidad social. Además, trae a la luz el materialismo de la nobleza y del clero, y las injusticias sufridas por los que carecen de posición importante en la sociedad, como los de las clases menos favorecidas, que viven a la merced de su propio destino; sometidos a las normas y leyes de la Iglesia y del Estado, cuya esperanza es en la vida eterna, donde se gozará la felicidad para siempre. El protagonista Tediato se convierte en el modelo reaccionario de una sociedad jerárquicamente tradicional; no puede disfrutar de su amor incondicional por su amada, dadas las circunstancias que le hacen fenecer. Así, lleva a cabo el plan de desenterrar su cadáver, algo que no conseguirá, evidenciando su desacuerdo con la doctrina cristiana que se "adueña" de los muertos, encargándose de sus cuidados y la conservación de sus restos mortales cementerios que son, tradicionalmente, propiedad de la Iglesia:

¡Ay, qué veo! Todo mi pie derecho está cubierto de ellos. ¡Cuánta miseria me anuncian! En éstos, ¡ay!, en éstos se ha convertido tu carne! ¡De tus hermosos ojos se han engendrado estos vivientes asquerosos! ¡Tu pelo, que en lo fuerte de mi pasión llamé mil veces no sólo más rubio, sino más preciosos que el oro, ha producido esta podre! ¡Tus blancas manos, tus labios amorosos, se han vuelto materia y corrupción! ¡En qué estado estarán las tristes reliquias de tu cadáver! (CADALSO, 2006. pp. 383-384).

El período de publicación de las Noches Lúgubres coincide con una etapa muy importante en Europa, la Revolución Francesa. Eso significa que existe en la atmósfera europea una significativa agitación política, social y cultural que abarca todas las capas de la sociedad. La literatura es responsable de mostrar esta realidad, de registrar los hechos que ocurren, además de llamar la atención sobre la necesidad de no perder el tren de la modernidad y acompañar estas transformaciones que dan lugar a la construcción de las nuevas sociedades y las formas que surgen de los comportamientos individuales y colectivos. Son cambios significativos que necesitan la participación de toda la sociedad.

La sólida formación del escritor y su manera irreverente de escribir, con el rechazo de lo preestablecido, le convierte en blanco de críticas y censura por parte de las jerarquías vigentes. Sin embargo, la censura no logra impedirle su actividad literaria y tampoco poda su decisión de transmitir las inquietudes del hombre ilustrado con la preciada arma de la palabra. 


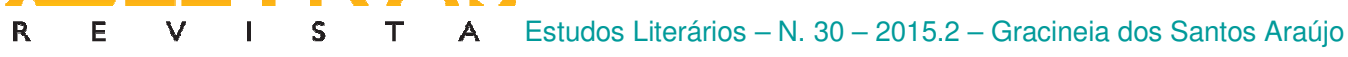

El tema del suicidio, presente en Noches Lúgubres, no es un tema exclusivo de la obra de Cadalso. Tampoco se trata de un tema inédito en España, pero sí es nueva la forma de escribir literatura en el país. El referido tema tiene tradición en la literatura folklórica española e incluso en la literatura universal.

La influencia de las Noches Lúgubres se hizo notar muy pronto en escritores como Meléndez Valdés y hasta en el siglo XIX como en las obras de Bécquer. La obra tiene en el protagonista Tediato la figura del romántico egoísta, no obstante refleja su sensibilidad ante los deseos de transformación social y su enorme preocupación por la colectividad. Tediato es capaz de cambiar de planes, de decir no a sus ideas convergentes hacia la satisfacción de lo personal, que es el deseo de alcanzar la muerte como forma de realización de sus egoísmos y seguir adelante, en búsqueda de la construcción de una sociedad donde la justicia sea justa y el cielo trate a todos de igual manera.

La manera como Cadalso escribe demuestra su pleno uso de la razón, impregnado del deseo y necesidad de la construcción de una nueva sociedad; posee la inquietud por una literatura desligada de la tradición pedagógica y moralizante, además de la necesidad de ofrecer a la población española una nueva literatura; mostrar los cambios existentes en otros horizontes y despertar el saber por temas de carácter humano, colectivo y universal para poder empezar a construir una nueva España, desligada del mundo medieval y con mirada positiva hacia la modernidad.

Cadalso está al tanto de lo que ocurre en el resto de Europa y, con su mirada atenta, refleja en su literatura el deseo del hombre ilustrado de cambios de valores y posturas, a partir de una mirada fija, cargada de sentimiento humano y avidez de transformación. De esta forma, reúne en su obra el deseo y las necesidades del hombre de la España dieciochesca; denuncia las injusticias existentes en ella y hace un llamamiento de atención para la necesidad de construir una nueva sociedad.

En esta reflexión subrayamos la importancia de las Noches Lúgubres en la construcción de la nueva sociedad, puesto que trae en ella las inquietudes del hombre ilustrado y su deseo de una sociedad más justa y más humana, liberada del autoritarismo de la Iglesia y del Estado. La obra de Cadalso no es simplemente autobiográfica (SEBOLD, 1974), sino el reflejo de una sociedad turbulenta. Más que el testimonio autobiográfico de Cadalso, es la voz de los que no tienen voz y el anuncio de las luces venidas del resto de Europa, ya que el autor, a través de la figura de Tediato, revela el tedio existente en la España dieciochesca, principalmente en el ámbito cultural y literario, cuya producción no va más allá de la religión y de la moral. Se busca la realización personal y colectiva del ser humano a través de una sociedad guiada por 
R $\quad$ E V V I $\quad$ S $\quad$ T A Estudos Literários - N. 30 - 2015.2 - Gracineia dos Santos Araújo

las luces de la razón, apartada de dogmatismos que perpetúan ideas antes consideradas como verdades absolutas, no dignas de ser cuestionadas.

El sueño de Tediato de suicidarse al lado del cadáver de su amada y la propuesta de suicidio colectivo que hace a Lorenzo son ejemplos de desesperación ante una sociedad que no presenta signos visibles de mudanza. No obstante, el pleno uso de las facultades mentales, el no perder la cordura, hace que se vislumbre la posibilidad de una sociedad redimensionada, que bebe en el pozo del saber producido en el extranjero, basada en la creencia de las luces que traen al panorama nacional la realización de este deseo de transformación socio-cultural y que abarca todos los recovecos de la sociedad. El intento y deseo de suicidio del protagonista de las Noches Lúgubres demuestra una contundente forma de decir no al orden establecido y hace un llamamiento a toda la sociedad de España para no perder el tren de la modernidad.

En efecto, al no llevar a cabo el suicidio pretendido, esta decisión de Tediato está impregnada de constantes reflexiones acerca de los nuevos rumbos que necesita tomar la España dieciochesca. Su reintegro a la sociedad no significa el conformismo ante las circunstancias vigentes a lo largo de todo el siglo XVIII, heredadas del siglo anterior, sino el candente deseo de mantener la lucha a favor de la construcción del nuevo panorama nacional, cuya prioridad es el bienestar de la colectividad y con vistas al futuro de forma no tradicional. La muy firme y constante intención del suicidio es una forma de protestar contra las injusticias sociales y el decir un no contundente a las trabas impuestas por la religión: “¡Ven, muerte, con todo tu séquito. Sí; ábrase esa puerta; entren verdugos feroces manchados aún con la sangre que acaban de derramar a una vara de mí. Si el ser infeliz es culpa, ninguno más reo que yo! (CADALSO, 2006. p. 398).

Noches Lúgubres constituye una crítica contundente a la sociedad dieciochesca y presenta una nueva forma de ver el mundo y actuar sobre él. Además, se suma a una nueva forma de expresión del pensamiento y de la literatura; está impregnada de denuncia social. Se trata de una obra por medio de la cual el autor refleja su inconformidad ante la oscuridad en la que vive el país; un ambiente "lleno de aflicciones, privado de bienes, con mil enemigos por fuera y un tormento interior capaz, por sí solo, de llenarme de horrores, aunque todo el orbe procurara mi infelicidad" (CADALSO, 2006. p. 405).

Además de mostrar un retrato del siglo XVIII en España, la obra de Cadalso plantea la total innovación de la sociedad, en todos los ámbitos. Al final, el protagonista no lleva a cabo el suicidio pretendido. Es una demostración de que las estructuras sociales dieciochescas tienen un papel muy importante en la formación de los individuos. El razonamiento de Tediato y el florecimiento del fervor revolucionario no le distancian totalmente de las 
R E V I S T A Estudos Literários - N. 30 - 2015.2-Gracineia dos Santos Araújo

enseñanzas de la iglesia católica, aunque esta sea el blanco de constantes críticas; plantea cambios significativos para toda la sociedad, no obstante está impregnado de la ortodoxia vigente.

La literatura cadalsiana irrumpe en la España dieciochesca como un arma cargada de sátira. Trae a la luz los escándalos ocasionados por los hombres y mujeres de bien, personajes de la alta sociedad madrileña que fingen fidelidad en las relaciones amorosas, pero mantienen relaciones ilícitas fuera del matrimonio. Es una denuncia vehemente del falso moralismo reinante en algunas familias católicas, consideradas como modelo de la sociedad y que debe ser seguido por todos. El propio Cadalso no lleva una vida digna de imitación. La irreverencia de su conducta personal y su sátira literaria le llevan al destierro de la Corte, de donde sale miserable y enfermo. Al salir desterrado, empieza una nueva etapa en la vida del tediático joven, pero la buena compañía de su musa le da inspiración para seguir adelante.

Gran parte de la vida de Cadalso está cargada de tedio. La turbulenta infancia, carente de apoyo psicológico de la familia y sus constantes traslados le aíslan de la vida convencional y de la ciudad. Todo le agobia, todo le molesta y hace surgir el deseo de la vida sencilla en una aldea. La naturaleza se convierte en una especie de refugio para su soledad, su tedio y su aburrimiento. La muerte de la amada marca profundamente la vida del autor. El amor incondicional de María Ignacia por el desheredado es el gran alivio de sus pesadumbres: "la mujer del mayor talento que yo he conocido, y que tuvo la extravagancia de enamorarse de mí, cuando yo me hallaba desnudo, pobre y desgraciado", confiesa en su Autobiografía (SEBOLD, 2006. p. 28).

La obra de Cadalso coincide con las muy tempranas muestras del Romanticismo alemán, aunque se publique posteriormente a la producción alemana. En efecto, es importante señalar la influencia de Noches Lúgubres en escritores como Meléndez, Jovellanos y Trigueros, entre otros. Todos estos autores aluden en su obra el tema del suicidio, uno de los principales objetivos del protagonista Tediato. Con base en esta perspectiva, y según subraya Sebold (2006), Cadalso podría ser considerado el Werther español, aunque haya sido escrita mucho antes, dado su sufrimiento y desesperación, reflejados en la obra. El dolor de Tediato, el protagonista, empieza con la muerte de su amada, la inesperada muerte.

El siglo XVIII es un tiempo en el cual abunda mal du siècle, afectando, principalmente, a los jóvenes. En este sentido, se hace notar la influencia de Noches Lúgubres en la sociedad española dieciochesca, como una obra que supone un peligro para la vida de los descreídos y rebeldes lectores jóvenes. La vida, en todas sus manifestaciones, tiene lugar en la obra de Cadalso. No obstante, es la muerte la que se destaca a través del deseo del protagonista de 


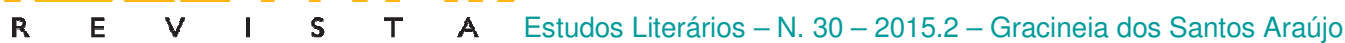

llegar a ella por vía propia. En ella tiene lugar, además, los problemas del hombre y de la humanidad, sus aspiraciones y necesidades; sus tristezas, sus dudas, sus sueños y esperanzas.

¿Para pasar cincuenta años de vida como la que he pasado, lleno de infortunios; y cuando apenas tengo fuerzas para ganar un triste alimento... hallarme con tantas nuevas desgracias en mi mísera familia, expuesta toda a morir con su padre en la más espantosa infelicidad? Amigo, si para eso deseas que me guarde el cielo, ;ah!, pídele que me destruya (CADALSO, 2006. p. 409).

La obra es un poema en prosa, a través del cual se introduce en la literatura española el dolor romántico. Para Sebold (2006), este dolor se presenta por medio del tema del doble suicidio que caracteriza la obra, además del ambiente lúgubre en el cual se desarrollan los hechos, lo que favorece su interpretación romántica. El dolor y el sufrimiento, sumados a la desesperación del protagonista, son elementos que más despiertan la tención de los lectores y de la crítica. La angustia del protagonista Tediato parece no tener fin. Todo en él es tristeza, dolor y desengaño. Por esta razón, la persecución del suicidio que lleva a cabo consiste en la única forma de mitigar las tormentas de la vida, ya que vivir es sinónimo del más profundo dolor. Por eso, el deseo insaciable de quitarse la vida aumenta día tras día, a raíz de que el amante se siente un desgraciado, maltratado por el cielo y por la tierra (la sociedad). De ahí que, para el protagonista, quitarse la vida es una forma de librarse de las injustas trabas religiosas y sociales que privan a los seres humanos de la felicidad terrenal.

Con base en esta perspectiva, es importante recordar que el tema del suicidio como sinónimo de escapismo no es propio de la obra de Cadalso, sino que aparece con bastante frecuencia en la producción literaria nacional. Un ejemplo de ello es la obra El delincuente honrado, de Jovellanos (1773); posteriormente a Noches Lúgubres, el poema La tormenta (1810-1820), de Martínez de la Rosa, entre otras.

Al contener expresiones consideradas escandalosas y peligrosas, Noches Lúgubres queda, durante mucho tiempo, condenada por la censura por la supuesta intención de despertar en algunos lectores el interés por el suicidio y fomentar el odio entre las personas. Aunque el suicidio del protagonista no se haya llevado a cabo, para muchos inquisidores, la obra tiene gran poder de influencia y no puede escapar de la censura, debido al tono crítico e irreverente que desarrolla el autor. Lo que más sobresale en el poema no es su grado de romanticismo o el hecho de que el protagonista no lleve a cabo el suicidio, aunque lo persiga constantemente, sino la forma obsesionada con la que el autor trata el tema del suicidio. Conforme Sebold (2006, p.83), "el suicidio que nunca se ejecuta en la carne, pero sigue 


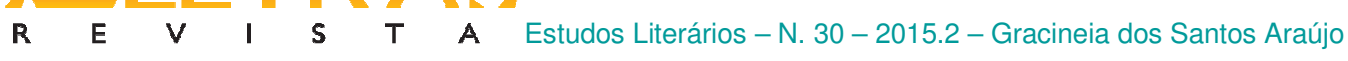

contemplándose, es una más dolorosa, por más lenta, muerte voluntaria, y brinda al escritor infinitas más posibilidades líricas que el brusco e irrevocable desenlace sangriento.

Para entender mejor la obra de Cadalso es necesario, además, tener en cuenta su sólida formación europea, principalmente inglesa y francesa. Ello ha favorecido el surgimiento de una obra tempranamente romántica y de considerable radical novedad. No obstante, tampoco hay que negar la influencia de la literatura hispánica, aunque en menor grado. Noches Lúgubres aparece mencionada ya en otras obras de Cadalso, anteriormente escritas, como en las Cartas Marruecas. En general, se trata de obras consideradas como un capricho literario del autor. El autor es consciente de la importancia de sus textos en la sociedad dieciochesca, de la repercusión entre los lectores jóvenes y el interés que fomentaría en la crítica de la época.

Tal es el éxito de Noches Lúgubres que se llega a creer que Cadalso, al igual que Tediato, el protagonista de su obra, llega a planificar el desenterramiento del cadáver de su amada y exhumarlo. Eso demuestra la gran publicidad e influencia que tiene la obra en el territorio nacional. El propósito inicial de Tediato no se lleva a cabo y, al final de la obra, el lector se encuentra ante las ganas de vivir que tiene el protagonista: "Andemos, amigo, andemos" (CADALSO, 2006, p.410). Con estas palabras desaparece todo el ambiente sepulcral de la obra y la naturaleza parece impregnarse de luces, las luces de la razón que hacen que el enamorado emprenda un nuevo propósito para su vida y la de su acompañante Lorenzo, el sepulturero. Tediato, además de ser un romántico, es un hombre ilustrado y no prescinde de los razonamientos ni de proyectar el futuro; busca, de manera constante, encontrar una solución para los problemas, pero es invadido por el dolor interior y las sombras tormentosas que le rodean. El miedo no le abandona y este es un sentimiento que favorece el uso de la razón. La consciencia de la transitoriedad de la vida y de las mismas condiciones humanas a las que todos están sometidos, por el simple hecho de ser humano, son cuestiones que forman parte de los razonamientos de Tediato.

Según subraya Glendinning (1993), el autor romántico tiene muchas preocupaciones por el presente y el futuro de la sociedad; bebe en fuentes tradicionales y de ellas acata la moralidad y el uso de la razón. Esto le hace comprometerse con las cuestiones relacionadas con las estructuras convencionales, como la familia y rechazar el orden establecido y las jerarquías. Además, mantiene una enorme preocupación por la búsqueda de la fraternidad humana, sin distinción de clase. De ahí que se evidencia que Cadalso bebe en fuentes literarias europeas, principalmente en la inglesa, una vez que en su obra se observa la gran aportación de esta literatura. Existe una influencia clara de la obra y del estilo del doctor 


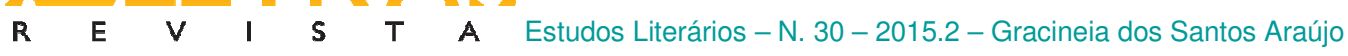

Young en cuanto al tema de la muerte. Elementos de la obra de Edward Young, símbolo de la literatura inglesa dieciochesca, están presentes muy significativamente en Noches Lúgubres. Entre ellos, el nombre del sepulturero Lorenzo y el ambiente nocturno en el que se desarrollan los hechos. Además, la postura contra la tradición católica tiene lugar asegurado en la literatura de ambos autores.

Desde la perspectiva de Sebold (2006), Noches Lúgubres es el primer poema en prosa de la literatura española. Es un poema lírico, rico en prosa, donde aparece el tema de mayor preferencia de los poetas líricos: el amor extravagante, un amor egoísta y yoísta, como el de Tediato. Con esta obra, Cadalso introduce el romanticismo en la sociedad de la España dieciochesca, una sociedad donde abundan las tormentas y los abismos sociales. De ahí que, es un gran observador del mundo que le rodea; se identifica con los sujetos que lo pueblan, con su sufrimiento y falta de perspectiva; participa psicológicamente de sus circunstancias. Todo ello, a través de las vicisitudes del protagonista de la referida obra.

No hay que olvidar que Noches Lúgubres no solo obtiene influencia de otras literaturas, sino que también influye en la escritura de muchos autores. De literatura española y universal el escritor obtiene temas fúnebres, cuyos argumentos son similares a su obra. Se trata leyendas diseminadas en Occidente, en las que se basan muchos romances populares españoles. Esta temprana obra romántica española tiene gran repercusión en la España dieciochesca, debido a su irreverente e innovadora literatura.

El mundo por el que se mueve el romántico es el menos frecuentado por gran parte de la sociedad. Un mundo poco convencional, falto de luz y de sombra abundante; lugares abstractamente idealizados. En este sentido, a través de Noches lúgubres el lector vislumbra estos lugares no por estar claramente mencionados, sino por las referencias que hay y que permiten trazarlo en la memoria: son calles, casas, templos...el tiempo en su totalidad no le importa a Tediato, sino parte de él, concretamente la noche. Aunque salga el sol, todo sigue siendo noche, todo sigue siendo oscuridad. Tediato vive en un mundo que es irreal para la realidad, alejado de las convenciones sociales, falto de objetividad; está encarcelado en su propio mundo, dentro de su propia psique.

La relación del romántico con el medio y el intento de ejercer su dominio sobre él hacen con que el poeta se sienta como Dios. El sentirse como el Creador, capaz de controlar el curso natural de la vida, aparece totalmente desligado de las creencias religiosas y de la fe cristiana. Este hecho demuestra la inexistente fe cristiana por parte del poeta. Existe una enorme dificultad del romántico para relacionarse con Dios y con los prójimos y eso le aleja todavía más de la sociedad, una sociedad fundamentada en ideales cristianos, perpetuados a través de 
R $\quad$ E V V I $\quad$ S $\quad$ T A Estudos Literários - N. 30 - 2015.2-Gracineia dos Santos Araújo

figuras humanas importantes. Estos ideales son continuamente rechazados por el yo romántico o de igual manera puestos en tela de juicio.

De manera clara, Cadalso evidencia su rechazo a la jerarquía eclesiástica y a la tradición cristiana en el cuidado de los muertos; subraya que todos, independientemente del status social que gozan, tendrán el mismo fin. Un ejemplo de ello es el de su enamorada, antes preciosa, llena de vigor...que, al morir, se pudre como los demás seres humanos, pasando a alimentar a otros seres, asquerosos y destruidores: los gusanos.

El protagonista de las Noches Lúgubres es únicamente contemplativo, un hombre de ideas, no de acción. En suspiros, demuestra su indignación ante el poder del dinero: "¡ay, dinero, lo que puedes!" (CADALSO, 2006, p.368). No obstante, la acción más pretendida durante su trayectoria no la realiza: la de desenterrar el cadáver de su amada y quemarse vivo junto a él. El angustiado encuentra gozo en el sufrimiento, en su propio sufrimiento y en el ajeno. Cuanto más sufre, más ganas tiene de seguir siendo el más sufridor de los sufridores. Para Sebold (2006), la idea de la muerte es una especie de sustento de las tormentas de la vida psicótica del angustiado, como podemos observar en el fragmento a continuación: "Tan despreciables son para mí muertos como vivos, en el sepulcro como en el mundo, podridos como triunfantes, llenos de gusanos como rodeados de aduladores" (CADALSO, 2006. p. 373).

El escritor ilustrado tiene en cuenta el pasado para entender el presente y poder transformarlo. En las Noches Lúgubres el protagonista, según Glendinning (1993), acata el imperio de la razón y de la moral tradicional y, por supuesto, actúa en la crítica a las estructuras convencionales, como la familia, y busca la fraternidad humana, sin distinción de clases. Además, tiene una enorme preocupación por los demás, puesto que lo más importante es la sociedad en su conjunto y no cada individuo de forma particular e individual.

Las injusticias afectan a toda la sociedad, principalmente a los más débiles, como Lorenzo, el sepulturero. Las condiciones infrahumanas a las que está sometido junto a su familia, la falta de perspectiva, son temas que preocupan e inquietan al hombre ilustrado. Lorenzo es la fiel representación de las injusticias sociales, del abandono y de la miseria humana. Por otro lado, Cadalso trae a la luz las condiciones de la cárcel, que es un verdadero sepulcro de vivos, morada de horror y de triste descanso en el camino del suplicio. En ese sentido, el escritor "apunta hacia la necesidad de reformas que proporcionaran un régimen más sano y más humanitario, con miras hacia la corrección más que al castigo" (GLENDINNIG, 1993. p. 49). 
R $\quad$ E $\quad$ V $\quad$ I $\quad$ S $\quad$ T $\quad$ A Estudos Literários - N. 30 - 2015.2-Gracineia dos Santos Araújo

Además de pobreza material, hay en la España dieciochesca pobreza de ideas. El prejuicio contra la vacuna es uno de los ejemplos del gran atraso social del país. El caos es tan evidente que en un determinado momento, ante las circunstancias de miseria y abandono a las que están sometidos Lorenzo y su familia, Tediado le recomienda el suicidio colectivo del sepulturero y lo que queda de los suyos. Todo en la vida del miserable Lorenzo es opresión y desgracia. Bajo estas condiciones no merece la pena seguir viviendo. Las ideas de Tediato alcanzan dimensiones inimaginables. Son ocurrencias que hacen que la sociedad levante su mirada y tome decisiones importantes para transformarla.

\section{Consideraciones finales}

La España del Siglo de las Luces padece un gran oscurantismo en el ámbito político, económico y social. Conflictos internos y externos de todo tipo inspiran a Cadalso a trazar el panorama histórico del país, partiendo de su propia experiencia. De ahí su esplendoroso vigor literario. En medio de la inquietud del presente y de la incertidumbre del futuro, el hombre ilustrado está caracterizado por el uso de la razón y por el deseo de cambio de la sociedad. Con base en esta perspectiva, resulta curioso hablar de noches, en pleno Siglo de las Luces.

¿Por qué aparecen las noches en un período conocido como Iluminismo? Esta es una pregunta que supone mucha reflexión. Por ello, reflexionar sobre Noches Lúgubres es un intento de comprender mejor esta época de la sociedad española y su importante aportación para la formación del pensamiento moderno.

Entender la conflictividad y el misterio de la sociedad ilustrada supone un gran desafío. Así, la lectura del pensamiento dieciochesco, sobre la postura de las jerarquías civiles y eclesiásticas, a partir de las Noches Lúgubres, consiste el punto de partida para llegar al entendimiento de una de las más importantes épocas de la historia de España.

Para finalizar, subrayamos que de la angustia y de la desesperación ante la realidad de la que forma parte el hombre dieciochesco surge la necesidad de procurar entender las circunstancias a las que está sometido. De ahí que trazar una imagen de la sociedad de ese momento consiste una de las principales formas de intentar transformarla, de evitar que se cometan tantos errores, como los del pasado, reflejados en fragmentos como en el que se habla del oro que se trajo "de la infeliz América a la tirana Europa" (CADALSO, 2006, p. 373), entre otros. 
R $\quad$ E $\quad$ V $\quad$ I $\quad$ S $\quad$ T $\quad$ A Estudos Literários - N. 30 - 2015.2-Gracineia dos Santos Araújo

\section{Bibliografía:}

AGUILAR PIÑAL, Francisco. La España del absolutismo ilustrado. Madrid: Espasa Calpe, 2005.

Historia literaria de España en el siglo XVIII. Madrid: Editorial Trotta: Consejo superior de Investigaciones Científicas, 1996.

ÁLVAREZ BARRIENTOS, Joaquín. La novela del siglo XVIII. Júcar. Madrid, 1999.

ANES, G. Economía e Ilustración en la España del siglo XVIII. Barcelona: Ariel, 1981.

AZORÍN. 1959, El romanticismo español. ABC, 1926-VI-18; reed. en Obras completas. Madrid: Aguilar, IX, 1072-1075, 1926.

CADALSO, J. Cartas Marruecas. Noches lúgubres. Madrid: Ed. Sebold, R.P; Cátedra, 2006.

CARNERO, G. La novela española del siglo XVIII: estado de la cuestión, Anales de Literatura Española, 11, 1995.

FOUCAULT, M. Sobre la Ilustración. Madrid: Tecnos, 2003.

GLENDINNING, Nigel. Lo gótico, lo funeral y lo macabro en la cultura española y europea del siglo XVIII, Anales de literatura española, 10, pp. 101-115, 1993.

. Vida y obra de Cadalso. Grados. Madrid, 1962.

HAZARD, P. La crisis de la conciencia europea (1680-1715). Madrid: Alianza, 1998.

MARAVALL, J. A. Estudios de la historia del pensamiento español (Siglo XVIII). Madrid: Mondadori, 1991.

MARTIN GAITE, C. Usos amorosos del dieciocho en España. Madrid: Siglo XXI, 1988.

SEBOLD, Russell P. (ed). CADALSO. J. Cartas Marruecas. Noches lúgubres. Madrid: Cátedra, 2006. Cadalso: el primer romántico europeo de España. Madrid: Gredos, 1974.

\section{Lights and shadows in the Spanish Age of Enlightenment: evaluation about the ideas come from Europe, reflected in the Noches Lúgubres work by José Cadalso}

Abstract: The current work tend to do a brief reflection about the ideas come from Europe and everything that it entails in the $18^{\text {th }}$ Spanish society, which is rural and agrarian yet, according to José Cadalso y Vázquez's view in the Noches Lúgubres work (1789-1790). The author, motivated due to French thinking arrival of Siècle des Lumières, based the reason on 
R E V I $\quad$ S $\quad$ T $\quad$ A Estudos Literários - N. 30 - 2015.2-Gracineia dos Santos Araújo

to find a possible solution for the issues which distress the society, revealing himself against the traditional and dogmatic.

Keywords: José Cadalso. Age of Enlightenment. Noches lúgubres.

Recebido em: 12 de setembro de 2015 .

Aprovado em: 01 de fevereiro de 2016. 